\title{
EL AMBIENTE DE APRENDIZAJE EN LA EDUCACIÓN CRISTIANA
}

\section{THE LEARNING ENVIRONMENT IN CHRISTIAN EDUCATION}

\author{
Raquel Inés Bouvet \\ Universidad de Montemorelos, México \\ rkorniej@um.edu.mx \\ https://orcid.org/0000-0001-6521-2280
}

\begin{abstract}
RESUMEN
Reseña de un libro: Kilgour, P. W. y Christian, B. J. (Eds.). (2019). Revealing Jesus in the learning environment: Experiences of Christian educators. Avondale Academic Press.
\end{abstract}

Palabras clave: ambiente de aprendizaje, educación cristiana

\section{ABSTRACT}

Book review: Kilgour, P. W. y Christian, B. J. (Eds.), (2019). Revealing Jesus in the learning environment: Experiences of Christian educators. Avondale Academic Press.

Keywords: learning environment, Christian education

En los últimos años, el ambiente de aprendizaje se ha convertido en un objeto de estudio en sí mismo debido a numerosas investigaciones que demuestran su importancia en el desempeño del estudiante. Sin embargo, en el marco de la educación cristiana, permanece sobre la mesa de discusión la pregunta sobre cómo los docentes cristianos, en ámbitos y contextos diferentes, revelan a Cristo a sus alumnos.

Esta obra es un compendio de contribuciones realizadas por docentes cristianos de distintas instituciones que ejercen en países/continentes diferentes, en distintos niveles y con diferentes metodologías y en contextos muy diversos.
Algunos aportes son informes de investigación y otros son propuestas didácticas basadas en prácticas exitosas.

Inicia la colección el informe de un estudio cualitativo que pretende responder a un interrogante permanentemente presente en la mente de docentes y directivos cristianos: los estudiantes icomprenden los elementos básicos de la fe cristiana en la escuela y pueden aplicar esta información a su vida después de graduarse? El resultado muestra que no queda claro que los docentes transfieran los contenidos de su fe, sino más bien que ayudan a sus estudiantes a transitar su ruta en la escuela. Muestra a docentes comprometidos, cristianos y afectuosos 
que hicieron el mayor impacto positivo, mientras que no se reflejaban con mucha fuerza los elementos de la verdad transferidos a su vida profesional. Otra investigación que profundiza en la relación docente-alumno muestra que los egresados de una institución cristiana describieron a sus consejeros memorables como quienes influyeron en su desarrollo de fe, mostrando un altruismo tal que sacrificaban sus propios intereses para atenderlos. Eran docentes que estaban profundamente comprometidos con ayudar a sus aconsejados a recuperarse de las dificultades de la vida y con entender su rol moral en la sociedad, persuadiéndolos en lugar de darles órdenes y orientándolos a visualizar el futuro. Adicionalmente, los ayudaban a entender e interpretar la realidad para guiarlos en la toma de decisiones sabias, pesando las consecuencias.

Algunos estudiantes llegan a las instituciones educativas golpeados por circunstancias difíciles de la vida. En muchos casos, la conducta del estudiante refleja los traumas o las situaciones que lo quebrantaron. En ese sentido, "el regalo más restaurativo y sanador que podemos ofrecer a nuestros alumnos es una relación amorosa y sanadora. Y es allí donde el docente entra en juego. Nosotros, como educadores tenemos la oportunidad de unirnos a Jesús en extender una atención positiva incondicional a nuestros estudiantes" (p. 109). Se trata de un espacio donde la conexión docente-alumno y la corrección van de la mano.

El clima escolar y el desarrollo de la fe van de la mano en una escuela. Así lo explica un estudio realizado en Australia que utilizó un modelo de ecuaciones estructurales para mostrar que, al mejorar el clima escolar, se mejoran las actitudes hacia las prácticas cristianas de los estudiantes y viceversa.

Aunque la escuela procura desarrollar la fe de todos los estudiantes, tiene un impacto mayor si el estudiante tiene un trasfondo de fe, que si no lo tiene. En una investigación al respecto, los estudiantes identifican los cultos en la escuela, los devocionales y las clases de Biblia/Religión como los espacios con mayor impacto positivo. Algunos de los estudiantes que no tienen un trasfondo de fe perciben que estas actividades los conducen a perder su interés por las cosas espirituales.

Entre las propuestas prácticas para que el estudiante aproveche el ambiente de aprendizaje, Kilgour presenta un análisis del método de Cristo en la interacción con distintas personas en contextos diferentes e informales, utilizándolos como herramientas naturales de aprendizaje, y propone que los docentes de hoy utilicen el mismo método. A su vez, Marion muestra cómo las instituciones cristianas pueden incluir a los estudiantes con discapacidades en sus aulas y cómo potenciar el aprendizaje de todos.

La relación entre los maestros y los alumnos tiene un gran impacto sobre los estudiantes, especialmente si esta relación es de calidad. No solamente es importante la relación del alumno con el docente, sino también con otros miembros del personal con los que interactúa en la cultura de la escuela, ya que el estudiante percibe a cualquier personal de la escuela como maestro.

Finalmente, la obra considera el lugar de la oración y la fe en la escuela, el rol de las emociones en el desarrollo de la fe, el poder de la palabra y del contacto humano y el concepto de autoestima a la luz del amor de Dios para el ser humano. 


\section{BOUVET}

La obra está dirigida especialmente a docentes y administradores de instituciones educativas cristianas. Su lectura estimula a realizar investigaciones sobre las prácticas similares a las presentadas en la obra para profundizar en la calidad de la educación cristiana. También inspira a experimentar nuevas maneras de reflejar a Jesús, independientemente del contexto de aprendizaje y de las condiciones de los estudiantes.

Recibido: 8 de abril de 2021 Revisado: 24 de mayo de 2021 Aceptado: 30 de mayo de 2021 